\section{Sensory Attributes of Juice from North American-Grown Elderberry Cultivars}

\author{
Michele Warmund ${ }^{1}$ \\ Division of Plant Sciences, University of Missouri, 1-59 Agriculture \\ Building, Columbia, MO 65211
}

Misha Kwasniewski and Janelle Elmore
Department of Food Science, University of Missouri, 135 Eckles Hall,
Columbia, MO 65211

Andrew Thomas

Division of Plant Sciences, University of Missouri, Southwest Research Center, Mount Vernon, MO 65712

\section{Koushik Adhikari \\ Department of Food Science and Technology, University of Georgia, 1109 Experiment Street, Griffin, GA 30223}

Additional index words. Sambucus, descriptive analysis, juice color, $\mathrm{pH}$, soluble solids, titratable acidity

\begin{abstract}
Various elderberry (Sambucus sp.) cultivars, including Bob Gordon, Marge, Ocoee, Ozark, Wyldewood, and York, have been selected primarily for plant productivity in North America and are most often processed into juice-based products. This study was conducted to quantify juice characteristics and to evaluate sensory attributes of juice from six elderberry cultivars using descriptive analysis. Hue angle values of 'Bob Gordon' and 'York' juices were low as compared with others tested. Soluble solids and titratable acidity of juices from 'Wyldewood' and 'York' were lower than those from other cultivars. Trained panelists identified 24 terms for descriptive analysis of elderberry juices. Of these $\mathbf{2 4}$ attributes, juices were highly characterized by a processed aroma, and several flavors, including processed, elderberry, fruity, and sweet. Unique juice descriptors for North American-grown elderberry cultivars included apple, beet, caramelized, fermented, processed, and pomegranate flavors, as well as astringent mouthfeel. Juices from elderberry cultivars differed in intensity ratings of nine attributes, including fruity, floral, sweet aromatics, bitter, sour, and sweet flavors, bitter and sweet aftertastes, and astringent mouthfeel. 'York' juice generally had high intensity ratings for sweet aromatics and sweet flavors, and relatively lower ratings for bitter aftertaste and astringent mouthfeel as compared with juices from other cultivars. This study provided key elements for future elderberry sensory research in the development of a formal lexicon for juice with defined attributes.
\end{abstract}

Interest in growing elderberry (Sambucus sp.) has surged in the past few years in Europe and North America due to the potential for high economic returns for producers and increased consumer interest in healthpromoting food products (Charlebois et al., 2010). Currently, the most common elderberry products purchased by consumers are juice, jelly, and wine (Mohebalian et al.,

Received for publication 23 Aug. 2016. Accepted for publication 11 Oct. 2016.

This project was supported by the Specialty Crop Block Grant Program at the U.S. Department of Agriculture (USDA) through grant 14-SCBGP-MO-0029.

The contents of this project are solely the responsibility of the authors and do not necessarily represent the official views of the USDA. ${ }^{1}$ Corresponding author. E-mail: warmundm@, missouri.edu.
2012). In a 2009 survey, elderberry products also ranked eighth in sales (over $\$ 6.8$ million) among botanical dietary supplements in the United States (Cavaliere et al., 2010).

To improve plant productivity and satisfy increased market demand for these products, elderberries from various locations have been selected and evaluated for flowering, date of fruit ripening, yield, and pest resistance (Finn et al., 2008). 'Bob Gordon', 'Ocoee', 'Ozark', and 'Wyldewood' are American elderberries [Sambucus nigra L. ssp. canadensis (L.) Bolli] selected from the wild in Missouri, Tennessee, Arkansas, and Oklahoma, respectively, that have been available for commercial production since 2011 (Thomas et al., 2015a). The cultivar York is also an American elderberry that was released by the New York Agricultural Experiment Station in 1964 (Greene et al., 1997). More recently, 'Marge' was selected from Kansas and is a highly productive European elderberry (Sambucus nigra ssp. nigra) (Thomas et al., 2015b). When nine elderberry cultivars were grown in research trials conducted at three Missouri sites, 'Marge' plants produced the greatest number of cymes and were the highest yielding (Thomas et al., 2015b).

Total anthocyanin content, phenolics, and other compounds extracted from elderberry fruit and juice have been studied due to their potential use in dietary supplements and medicinal products. Kaack et al. (2008) identified neochlorogenic acid, chlorogenic acid, cyanidin-3-sambubioside-5-glucoside, cyanidin3,5-diglucoside, cyanidin-3-sambubioside, cyanidin-3-glucoside, quercetin-3-rutinoside (rutin), and quercetin-3-glucoside (isoquercetin) in juice preparations from selected European elderberry genotypes. Other studies evaluated total phenolics and total monomeric anthocyanin contents to assess variability among American elderberry accessions and cultivars (Lee and Finn, 2007; Nakatani et al., 1995; Özgen et al., 2010; Perkins-Veazie et al., 2015; Thomas et al., 2013; Wu et al., 2015). Although phenolic and anthocyanin contents differed by genotype, production site, and annual climatic conditions, 'Bob Gordon' had high levels of these compounds as compared with other cultivars tested in North America (Lee and Finn, 2007; Perkins-Veazie et al., 2015; Thomas et al., 2013; Wu et al., 2015).

In addition to polyphenols, the aromatic composition of elderberry has been characterized. Fifty-nine volatile compounds were identified from processed juice of European elderberries grown in Denmark (Kaack et al., 2005). Compounds associated with elderberry, fruity, floral, and green aromas, as well as other odors were correlated with elderberry flavor intensity. The characteristic elderberry aroma was attributed to nonanal, dihydroedulan, and $\beta$-damascenone. Fruity aromas were associated with esters of lower carboxylic acids and alcohols; floral and floral green odors with hotrienol, linalool, and other terpenoids; and green aromas with 1-hexanol, (Z)-3-hexen-1-ol, (E)-2-hexen-1ol, $(E)-2$-hexenal, and hexanal (Jensen et al., 2001; Kaack, 2008; Kaack et al., 2005; Poll and Lewis, 1986).

Sensory attributes for juice flavor have received less attention than analysis of their aroma profiles, especially for American elderberry. In the Czech Republic, 17 European elderberry cultivars were evaluated for appearance, juiciness, aroma, flavor, and overall taste (Kaplan et al., 2015). 'Dana', 'Heidegg 13', 'Samdal', and 'Weihenstephan' generally had the highest overall taste ratings among the elderberry cultivars tested. However, with the exception of 'Samdal', many of the elderberry cultivars grown in Europe are unavailable in North America. In addition, intensities of specific sensory attributes have not been quantified by descriptive analysis for elderberry cultivars commonly grown in North America. Therefore, the objectives of this study were to identify and evaluate aroma, flavor, and mouthfeel 
attributes of juice from six elderberry cultivars using descriptive sensory analysis and to compare juice color and composition (soluble solids, $\mathrm{pH}$, and titratable acidity).

\section{Materials and Methods}

Plant material and sample collection. A planting of elderberry cultivars was established in April 2008 at the University of Missouri Southwest Research Center near Mount Vernon, MO. The soil at this site is a Hoberg silt loam (fine-loamy, siliceous, mesic Mollic Fragiudalfs), which is moderately well drained with a fragipan at 40 to $90 \mathrm{~cm}$ below the soil surface. Four replications of four plant plots of each cultivar (Bob Gordon, Marge, Ocoee, Ozark, York, and Wyldewood) were arranged in a completely randomized design using a $1.2 \mathrm{~m} \times 2.4 \mathrm{~m}$ spacing. Nitrogen fertilizer was applied in March at $56 \mathrm{~kg} \cdot \mathrm{ha}^{-1}$ annually. Plants were irrigated weekly to provide 2.5 to $4.0 \mathrm{~cm}$ water. Weeds were controlled manually and the fescue groundcover was mowed. Fruit was harvested at peak ripeness (e.g., all fruit in cyme dark purple color) from 4 to 18 Aug. 2014. Immediately after harvest, berries were washed, destemmed, sealed in polyethylene bags, and stored at $-20{ }^{\circ} \mathrm{C}$ until juice extraction.

Juice color and fruit compositional analysis. For color measurements, a 200-g berry sample of each cultivar (composite sample from all harvest dates) was thawed and pressed in a sieve for juice extraction. A $10-\mathrm{mL}$ juice sample was then placed in a cuvette in a cell holder attached to a handheld spectrophotometer (CM-2600d; Konica Minolta, Ramsey, NJ) with a 6-mmdiameter aperture. For each measurement, the D65 illuminant, a $10^{\circ}$ observer setting, and the specular light excluded mode of the spectrophotometer were used, as well as the standardized Commission Internationale de I'Eclairage color values (Konica Minolta, 2007). The $\mathrm{L}^{*}$ value ranges from 0 (black) to 100 (white) (Voss, 1992). Chroma (C) is the departure from white toward pure hue color and represents brightness (McGuire, 1992). Hue angle quantifies color, where $0^{\circ}=$ red, $90^{\circ}=$ yellow, $180^{\circ}=$ green, and $270^{\circ}=$ blue (Konica Minolta, 2007). Two readings of juice color values $\left(\mathrm{L}^{*}\right.$, chroma, and hue angle) for each sample were averaged, and for each cultivar, three replications of each juice sample were evaluated.

For fruit compositional analyses, $50 \mathrm{~g}$ of thawed fruit of each cultivar (composite sample from all harvest dates) was placed in a Waring blender (Stamford, CT) cup with $50 \mathrm{~mL}$ double-distilled water and processed for $30 \mathrm{~s}$ (Thomas et al., 2013). The puree was then strained in a sieve to remove the seeds. A $0.3-\mathrm{mL}$ aliquot of puree was used for soluble solids measurements with a digital refractometer (Atago USA, Bellevue, WA) and $10 \mathrm{~mL}$ of puree was used to determine $\mathrm{pH}$ (HI 2222 pH meter; Hanna Instruments, Woonsocket, $\mathrm{RI})$. Another aliquot of puree $(10 \mathrm{~mL})$ was then diluted with $40 \mathrm{~mL}$ double-distilled water and titrated manually to an endpoint of $8.2 \mathrm{pH}$, using a burette containing $0.1 \mathrm{~N}$
$\mathrm{NaOH}$ and a $\mathrm{pH}$ meter. Titratable acidity, expressed as citric acid, was then calculated. Three replications of puree were prepared from the composite fruit from each cultivar and were used for soluble solids, $\mathrm{pH}$, and titratable acidity measurements.

Sensory analysis. To prepare each juice sample for sensory analysis, $800 \mathrm{~g}$ of fruit of each cultivar (composite sample from all harvest dates) was placed in $1600 \mathrm{~mL}$ water and was heated to $80{ }^{\circ} \mathrm{C}$. After $5 \mathrm{~min}$, the mixture was pressed through a sieve for juice extraction. After juice was cooled to $21^{\circ} \mathrm{C}$, sucrose was added to each sample to attain $13{ }^{\circ}$ Brix. The addition of sucrose was necessary to make juice palatable for sensory panelists. Samples were stored at $-20{ }^{\circ} \mathrm{C}$ before shipping by overnight mail to the Sensory Evaluation Laboratory (SEL), Griffin, GA, for sensory analyses.

A descriptive sensory analysis panel composed of six highly trained panelists (between 22 and 60 years of age) from the SEL participated in this study. Each panelist had more than $120 \mathrm{~h}$ of descriptive analysis training and averaged more than $1200 \mathrm{~h}$ of testing experience on many different product categories, including blueberries, peaches, and cantaloupes. Descriptive terms were generated during four 2-h orientation sessions. In the first three sessions, attributes and references were determined, anchored to the scale, and reviewed to ensure understanding of the terms. Each panelist was presented a selection of elderberry juice samples to taste and identify sensory characteristics that discriminated the samples. Each of the attributes was evaluated using a 0 - to $150-\mathrm{mm}$ line scale $(0=$ none to $150=$ extreme $)$ with $1-\mathrm{mm}$ increments (intensity of references were provided for the attributes). Panelists' understanding and ability to use the identified sensory characteristics were assessed during orientation sessions. Discrepancies regarding the understanding of terms were discussed and resolved during these sessions. In the fourth session, the panel came to consensus on 24 attributes (Table 1) to describe the samples, which were placed on the ballot for the blind evaluations.

After orientation sessions were completed, panelists evaluated samples in a well-lit (natural and fluorescent lighting) room at $22 \pm 1{ }^{\circ} \mathrm{C}$ and $\approx 55 \%$ relative humidity. All juice samples were evaluated in triplicate over three 2-h sessions, with each of the six cultivars presented at each session. A randomized complete block design was used to determine the serving order of the juice samples for each cultivar for each of the three sessions. Before serving, 200-mL juice samples of each cultivar were thawed $6 \mathrm{~h}$ at $22{ }^{\circ} \mathrm{C}$. Each $20-\mathrm{mL}$ sample was placed in a 30-mL plastic cup and covered with a lid for $10 \mathrm{~min}$ before serving. Panelists were instructed to sniff three times for the aroma descriptors and take a sip of each juice sample for flavor, aftertaste, and mouthfeel evaluations. Deionized water and unsalted crackers were served as palate cleansers. A minimum break of 2 min was taken between each sample. Ratings were collected using paper ballots.

Data analysis. Juice color ( $\mathrm{L}^{*}$, chroma, hue angle), soluble solids, $\mathrm{pH}$, and titratable acidity data were subjected to analysis of variance (ANOVA) using SAS (version 9.3; SAS Institute, Cary, NC) and means were separated by Tukey's honestly significant difference (HSD) at $P \leq 0.05$. ANOVA was also conducted for each sensory attribute with cultivar, replicate, and panelist, as well as all two-way interactions of these factors using PROC GLIMMIX. Panelists and replicates were treated as random effects. HSD tests were performed post hoc for those attribute means found significantly different across the samples by ANOVA $(P \leq 0.05)$. Data from chemical and sensory attributes that significantly discriminated among the samples were used in a principal components analysis (PCA). PCA was performed on the correlation matrix using JMP (version 9.3; Cary, NC). Following PCA, attributes with vectors in close proximity on the first two components were further analyzed using multiple regression.

\section{Results and Discussion}

Juice color and fruit compositional analysis. Undiluted juice samples had similar $\mathrm{L}^{*}$ values when evaluated for color (Table 2 ). However, chroma values were significantly higher for 'York' and 'Bob Gordon' juices than 'Ocoee', 'Ozark', and 'Wyldewood' samples. 'Bob Gordon' and 'York' juices had the lowest hue angle values and were visually browner than samples of other cultivars with a strong correlation found between hue angle and chroma values $\left(R^{2}=\right.$ $0.89, P=0.005)$. 'Wyldewood' and 'York' juices had the lowest soluble solids and titratable acidity (Table 2). Juice from 'Wyldewood' had a higher $\mathrm{pH}$ than that of other samples, except for 'York'. Results for soluble solids and $\mathrm{pH}$ in the present study are consistent with those reported in another 3-year study in which juice composition was compared for the same cultivars (Thomas et al., 2015b). Because soluble solids of elderberry juice are generally low, processors typically add high concentrations of sweeteners to their products, including sucrose, sorghum syrup, agave nectar, or pear juice. Products such as Elderberry Herbal Cordial (Elderberry Life, Pittsboro, NC), Biotta Elderberry Juice (CAJ Food Products, Carmel, IN), and Sanso Springs Elderberry Juice (Nevada, MO) range from 43 to $47^{\circ}$ Brix (M.R. Warmund, unpublished data), indicating these elderberry products are sweeter than the juice tested in the present study.

Sensory attributes. A total of 24 sensory attributes were used to qualify and quantify the juice from the elderberry cultivars in this study, including six aroma descriptors (fruity, elderberry, sweet, processed, fermented, and green/viney), 14 flavor attributes (apple, beet, caramelized, elderberry, fruity, fermented, processed, floral, pomegranate, sweet aromatics, green, bitter, sour, and sweet), three 
Table 1. Descriptive terms, definitions, and references used in the sensory analysis of juices from six North American-grown elderberry juices.

\begin{tabular}{|c|c|}
\hline Attribute and definition & References and anchors ${ }^{\mathrm{z}}$ \\
\hline \multicolumn{2}{|l|}{ Aroma } \\
\hline Elderberry: aromatics associated with elderberry fruit & $\begin{array}{l}\text { Elderberry extract (Dynamic Health Laboratories, Brooklyn, NY), } 50 \% \\
\text { solution }=25\end{array}$ \\
\hline Sweet: aromatic associated with sweet material & Clover honey (Great Value, Wal-Mart, Bentonville, AR) $=35$ \\
\hline $\begin{array}{l}\text { Processed: aromatic associated with processed, canned fruits, or } \\
\text { vegetables }\end{array}$ & Peach juice (Minute Maid, Sugar Land, TX) $=75$ \\
\hline
\end{tabular}

Flavor

Apple: a sweet, light, fruity, somewhat floral aromatic commonly associated with processed apple juice and cooked apples

Beet: the slightly sweet flavor commonly associated with canned/cooked beets

Caramelized: cooked flavor that may include the character notes identified as caramelized and associated with dates or other cooked fruit

Elderberry: flavor associated with elderberry fruits

Fruity: a general term used to describe the sweet, floral, fruity flavor associated with a blend of fruits

Fermented: flavor associated with fermented fruits or vegetables

Processed: flavor associated with processed, canned fruits or vegetables

Floral: sweet, light, slightly perfumery impression associated with flowers

Pomegranate: flavor associated with pomegranate fruit

Sweet aromatics: flavor associated with sweet material

Green: flavor associated with the green material

Bitter: the amount of bitter taste left on palate after expectoration

Sour: the basic taste associated with citric acid

Sweet: the basic taste associated with a sucrose solution

Bitter aftertaste: the amount of bitter taste left on the palate after expectoration

Sour aftertaste: the amount of sour taste left on the palate after expectoration

Sweet aftertaste: the amount of sweet taste left on the palate after expectoration

Mouthfeel

Astringent: the puckering or drying sensation on the mouth or tongue surface

${ }^{\mathrm{z}}$ Reference values anchored to a scale of 0 (no perception) to 150 (extreme perception).

Apple juice (Great Value, Wal-Mart, Bentonville, AR) $=70$

Canned beets (Kroger, Cincinnati, $\mathrm{OH})=70$

Elderberry jelly (Dutch Kettle, Hamptonville, NC) $=20$

Elderberry extract (Dynamic Health Laboratories, Brooklyn, NY), 50\% solution $=85$

Dates (Sunsweet, Yuba City, CA) $=45$

Dried figs (David Lewis Orchards, Garden Grove, GA) $=35$

Peach juice (Minute Maid, Sugar Land, TX) $=75$

Clover honey (Great Value, Wal-Mart, Bentonville, AR) $=50$

Pomegranate arils (DJ Forry, Reedley, CA) $=35$

Clover honey (Great Value, Wal-Mart, Bentonville, AR) $=35$

Homogenized, filtered parsley $(25 \mathrm{~g}$ fresh parsley and $300 \mathrm{~mL}$ water $)=40$

Caffeine (Sigma-Aldrich, St. Louis, MO), $0.8 \mathrm{~g} \cdot \mathrm{L}^{-1}$ solution $=20$

Citric acid (Sigma-Aldrich, St. Louis, MO), $0.5 \mathrm{~g} \cdot \mathrm{L}^{-1}$ solution $=20$

Sucrose (Kroger, Cincinnati, $\mathrm{OH}$ ), $50 \mathrm{~g} \cdot \mathrm{L}^{-1}$ sucrose solution $=50$

Caffeine (Sigma-Aldrich, St. Louis, MO), $0.8 \mathrm{~g} \cdot \mathrm{L}^{-1}$ solution $=20$

Citric acid (Sigma-Aldrich, St. Louis, MO), $0.5 \mathrm{~g} \cdot \mathrm{L}^{-1}$ solution $=20$

Sucrose (Kroger, Cincinnati, $\mathrm{OH}), 50 \mathrm{~g} \cdot \mathrm{L}^{-1}$ sucrose solution $=50$

Alum (McCormick \& Co., Hunt Valley, MD), $20 \mathrm{~g} \cdot \mathrm{L}^{-1}$ alum solution $=20$ aftertaste descriptors (bitter, sour, and sweet), and one mouthfeel attribute (astringent) (Tables 1 and 3). Elderberry juices were characterized by a processed aroma (61.9 to 67.8 mean intensity ratings), and several flavors, including processed (67.7 to 72.8 ratings), elderberry (55.0 to 62.5 ratings), fruity ( 38.6 to 46.4 ratings), and sweet (37.8 to 52.5 ratings). Lower impressions of fruity aroma, elderberry aroma, floral flavor, sweet aromatics, and sweet aftertaste (22.5 to 34.8 ratings) were also perceived in the juices. Lower, but detectable levels of the remaining attributes were also perceived $(\leq 22.9$ ratings). These results demonstrate an array of sensory attributes for juices from commonly grown elderberry cultivars in North America. Previous studies focused on evaluation of elderberry juice for appearance, fruitiness, floweriness, freshness, sweetness, sourness, bitterness, juiciness, aroma, flavor, and overall taste or on volatile compounds (Jensen et al., 2001; Kaack, 2008; Kaack et al., 2005; Kaplan et al., 2015; Poll and Lewis, 1986). Many of the volatile compounds of juice samples of European elderberry cultivars identified by gas chromatography were mostly associated with various fruity, floral, green, and sweet odors, but woody, mushroom,

Table 2. Mean juice color ( $\mathrm{L}^{*}$, chroma, hue angle) and fruit composition of six North American-grown elderberry cultivars. ${ }^{z}$

\begin{tabular}{lclcccc}
\hline Cultivar & $\mathrm{L}^{*}$ & Chroma & Hue angle & $\begin{array}{c}\text { Soluble } \\
\text { solids }\left({ }^{\circ} \mathrm{Brix}\right)\end{array}$ & $\mathrm{pH}$ & $\begin{array}{c}\text { Titratable acidity } \\
(\mathrm{g} / 100 \mathrm{~mL} \text { as citric acid })\end{array}$ \\
\hline Bob Gordon & 27.46 & $1.03 \mathrm{~b}$ & $27.80 \mathrm{~b}$ & $12.4 \mathrm{a}$ & $4.72 \mathrm{bc}$ & $0.28 \mathrm{a}$ \\
Marge & 27.26 & $1.00 \mathrm{bc}$ & $32.93 \mathrm{a}$ & $12.4 \mathrm{a}$ & $4.51 \mathrm{~d}$ & $0.32 \mathrm{a}$ \\
Ocoee & 27.35 & $0.97 \mathrm{~cd}$ & $32.69 \mathrm{a}$ & $12.1 \mathrm{a}$ & $4.70 \mathrm{c}$ & $0.30 \mathrm{a}$ \\
Ozark & 27.33 & $0.93 \mathrm{~d}$ & $35.35 \mathrm{a}$ & $12.3 \mathrm{a}$ & $4.59 \mathrm{~cd}$ & $0.31 \mathrm{a}$ \\
Wyldewood & 27.28 & $0.94 \mathrm{~d}$ & $33.44 \mathrm{a}$ & $10.4 \mathrm{~b}$ & $4.99 \mathrm{a}$ & $0.21 \mathrm{~b}$ \\
York & 27.45 & $1.08 \mathrm{a}$ & $26.22 \mathrm{~b}$ & $9.9 \mathrm{~b}$ & $4.87 \mathrm{ab}$ & $0.25 \mathrm{~b}$ \\
\hline
\end{tabular}

${ }^{2}$ Values represent the mean of three replications. Means with different letters in a column are statistically significant at $P \leq 0.05$ by Tukey's honestly significant difference test. $\mathrm{L}^{*}$ scale ranges from $0=$ black to $100=$ white. Chroma is the departure from white toward pure hue color and represents brightness. Hue angle quantifies color where $0^{\circ}=$ red, $90^{\circ}=$ yellow, $180^{\circ}=$ green, and $270^{\circ}=$ blue .

roasted nutty, and minty aromas were also identified (Kaack et al., 2005). Our study confirms that several of the attributes used for juice from $S$. nigra ssp. nigra cultivars grown in Europe are similar to those identified for juice from elderberries cultivated in North America, including 'Marge' (Kaack, 2008; Kaack et al., 2005; Kaplan et al., 2015). However, we identified additional elderberry juice descriptors, including apple, beet, caramelized, fermented, processed, and pomegranate flavors, bitter, sour, and sweet aftertastes, and astringent mouthfeel. Such differences in attributes may be due to different cultivars, experimental methods, or the growing environment. The development of a formal lexicon for American elderberry with definitions for each attribute in the present study is an additional contribution to elderberry sensory research.

Results from this study indicated that intensity ratings for each aroma attribute were similar among juice samples from all cultivars (Table 3 ). However, nine of the 24 sensory descriptors of elderberry juice flavors and mouthfeel varied significantly among cultivars. 'York' juice had relatively high intensity ratings for fruity, floral, sweet 
aromatics, and sweet flavors as compared with juice from other cultivars. Also, juice from 'York' generally rated lower for bitter aftertaste and higher for sweet aftertaste than juices from other cultivars. 'Ocoee' juice was the most dissimilar from 'York' samples, differing in nine sensory characteristics. Relative to 'York', juice from 'Ocoee' was significantly less flavorful (fruity, floral, sweet aromatics, sweet, and sweet aftertaste attributes) and more bitter, and sour in taste, bitter in aftertaste, and astringent in mouthfeel. Although sucrose was added to adjust juices to a similar soluble solids content, panelists perceived 'York' juice to have a sweeter initial flavor and aftertaste than juices from other cultivars. The reason for these perceptions is unclear, but may be related to the low titratable acidity and low intensity of bitter aftertaste of 'York' juice. Average intensity ratings for 'Ozark' juice were significantly more bitter (taste and aftertaste), sour, and astringent than those ratings for 'York' juice. Sensory attribute ratings were not significantly different among juices from 'Bob Gordon', 'Marge', and 'Wyldewood', except for the more bitter flavor of 'Marge' samples.

Results from the PCA showed that the first two principal components ( $\mathrm{C} 1$ and C2) accounted for $79.7 \%$ of the variation (Fig. 1). Component 1 explained $60.6 \%$ of the variability and was positively related to bitter and sour flavors, bitter aftertaste, and astringent mouthfeel, as well as hue angle. This component was strongly and negatively related to sweet flavor, sweet aromatics flavor, sweet aftertaste, and chroma. Component 2 explained $19.1 \%$ of the variability and was more heavily influenced by juice characteristics ( $\mathrm{pH}$, titratable acidity, and soluble solids). Fruity and floral flavors had relatively minor influences on $\mathrm{C} 1$ and $\mathrm{C} 2$. 'York' juice was separated from those of all other cultivars on $\mathrm{C} 1$, having the highest values for most of the taste attributes related to sweetness and among the lowest for attributes related to bitterness and sour flavors and astringency. 'York' also had the highest chroma value with 'Ozark' and 'Wyldewood' among the lowest, further defining the separation of the juice from these cultivars on C1. Juice from 'Marge', the only European elderberry cultivar included in this study, did not separate from juices of other cultivars studied on C1. However, 'Marge' juice was distinguished on $\mathrm{C} 2$, which was defined predominantly by $\mathrm{pH}$, soluble solids, and titratable acidity. When means of several of the important attributes for $\mathrm{C} 1$ were analyzed individually with chroma by linear regression, a strong negative correlation was found for bitter aftertaste $\left(R^{2}=0.73, P=0.03\right)$, sour taste $\left(R^{2}=0.83, P=0.012\right)$, and astringency $\left(R^{2}=0.78, P=0.014\right)$. However, hue angle was strongly correlated with sour taste $\left(R^{2}=0.82, P=0.013\right)$.

This research demonstrated that elderberry juices from 'Bob Gordon' and 'York' fruit differed in hue angle (i.e., visually browner in color) as compared with juices from other cultivars. Also, 'Wyldewood' and

Table 3. Mean sensory attribute intensity ratings of juice from six North American-grown elderberry cultivars. $^{z}$

\begin{tabular}{|c|c|c|c|c|c|c|c|}
\hline Descriptor & Bob Gordon & Marge & Ocoee & Ozark & Wyldewood & York & $P$ value \\
\hline \multicolumn{8}{|l|}{ Aroma } \\
\hline Fruity & 27.5 & 26.1 & 24.6 & 28.8 & 29.7 & 27.1 & 0.0870 \\
\hline Elderberry & 24.9 & 24.5 & 23.6 & 25.8 & 26.7 & 25.8 & 0.2618 \\
\hline Sweet & 19.6 & 22.9 & 20.6 & 21.6 & 20.3 & 21.2 & 0.1580 \\
\hline Processed & 65.8 & 64.2 & 61.9 & 65.4 & 67.8 & 67.5 & 0.5139 \\
\hline Fermented & 13.0 & 13.7 & 10.1 & 13.6 & 14.8 & 12.8 & 0.2571 \\
\hline Green/viney & 10.3 & 9.5 & 10.9 & 12.4 & 12.5 & 14.0 & 0.0790 \\
\hline \multicolumn{8}{|l|}{ Flavor } \\
\hline Apple & 21.2 & 19.7 & 18.2 & 19.7 & 17.1 & 20.6 & 0.7094 \\
\hline Beet & 20.1 & 14.7 & 18.3 & 16.9 & 19.6 & 19.3 & 0.0807 \\
\hline Caramelized & 17.2 & 15.5 & 16.3 & 15.2 & 16.9 & 17.5 & 0.4089 \\
\hline Elderberry & 58.9 & 57.1 & 55.0 & 62.5 & 55.2 & 58.3 & 0.1454 \\
\hline Fruity & $43.3 \mathrm{ab}^{\mathrm{y}}$ & $39.2 \mathrm{bc}$ & $38.6 \mathrm{c}$ & $43.8 \mathrm{a}$ & $43.5 \mathrm{ab}$ & $46.4 \mathrm{a}$ & 0.0064 \\
\hline Fermented & 14.0 & 16.9 & 13.9 & 14.1 & 16.4 & 16.8 & 0.6284 \\
\hline Processed & 72.8 & 71.3 & 69.4 & 71.7 & 67.7 & 72.5 & 0.5617 \\
\hline Floral & $27.1 \mathrm{ab}$ & $27.9 \mathrm{ab}$ & $23.5 \mathrm{c}$ & $28.1 \mathrm{ab}$ & $25.6 \mathrm{bc}$ & $28.9 \mathrm{a}$ & 0.0124 \\
\hline Pomegranate & 16.2 & 16.0 & 14.9 & 17.6 & 13.6 & 16.7 & 0.3530 \\
\hline Sweet aromatics & $22.8 \mathrm{~b}$ & $22.5 \mathrm{~b}$ & $22.5 \mathrm{~b}$ & $23.1 \mathrm{ab}$ & $22.8 \mathrm{~b}$ & $28.0 \mathrm{a}$ & 0.0137 \\
\hline Green & 13.9 & 14.6 & 14.9 & 16.5 & 15.1 & 16.0 & 0.6085 \\
\hline Bitter & $20.8 \mathrm{a}$ & $17.3 \mathrm{bc}$ & $20.3 \mathrm{ab}$ & $22.3 \mathrm{a}$ & $20.7 \mathrm{a}$ & $15.1 \mathrm{c}$ & 0.0001 \\
\hline Sour & $13.8 \mathrm{bc}$ & $14.8 \mathrm{bc}$ & $15.0 \mathrm{~b}$ & $18.3 \mathrm{a}$ & $15.4 \mathrm{ab}$ & $11.9 \mathrm{c}$ & 0.0032 \\
\hline Sweet & $38.1 \mathrm{~b}$ & $40.6 \mathrm{~b}$ & $37.8 \mathrm{~b}$ & $44.7 \mathrm{~b}$ & $42.5 \mathrm{~b}$ & $52.5 \mathrm{a}$ & 0.0032 \\
\hline \multicolumn{8}{|l|}{ Aftertaste } \\
\hline Bitter & $18.8 \mathrm{ab}$ & $17.4 \mathrm{bc}$ & $19.7 \mathrm{ab}$ & $20.8 \mathrm{a}$ & $18.7 \mathrm{ab}$ & $12.9 \mathrm{c}$ & 0.0001 \\
\hline Sour & 12.5 & 13.0 & 13.7 & 14.9 & 13.7 & 11.2 & 0.0687 \\
\hline Sweet & $25.2 \mathrm{~b}$ & $26.9 \mathrm{~b}$ & $23.3 \mathrm{~b}$ & $26.8 \mathrm{~b}$ & $24.8 \mathrm{~b}$ & $34.8 \mathrm{a}$ & 0.0006 \\
\hline \multicolumn{8}{|l|}{ Mouthfeel } \\
\hline Astringent & $19.4 \mathrm{ab}$ & $17.6 \mathrm{bc}$ & $21.0 \mathrm{a}$ & $21.8 \mathrm{a}$ & $20.6 \mathrm{ab}$ & $15.8 \mathrm{c}$ & 0.0036 \\
\hline
\end{tabular}

${ }^{\mathrm{z}}$ Attribute intensity was evaluated using a 0 - to $150-\mathrm{mm}$ line scale $(0=$ none to $150=$ extreme $)$ with 1 -mm increments.

${ }^{y}$ Means with different letters in a row are statistically significant at $P \leq 0.05$ by Tukey's honestly significant difference test.

\section{Biplot (axes C1 and C2: $79.69 \%$ )}

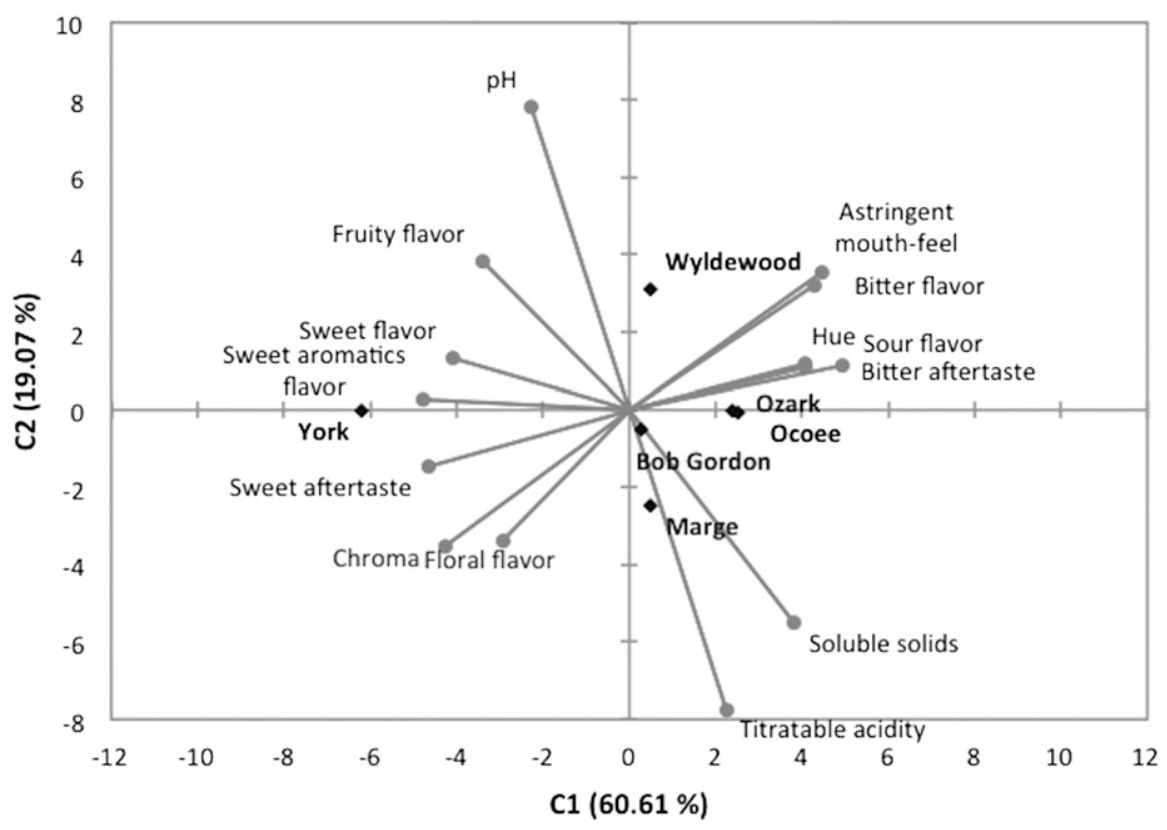

Fig. 1. Principal components analysis biplot showing the relationship between descriptive sensory attributes, juice color, and fruit composition of six North American-grown elderberry cultivars. $\mathrm{C} 1$ and $\mathrm{C} 2$ represent the first and second principal components, respectively.

'York' juice samples had the lowest soluble solids and titratable acidity. Using highly trained panelists, 24 attributes were used to describe sensory characteristics of elderberry cultivars currently grown in North America.
Although other research on elderberry juice has focused on volatiles to evaluate sensory characteristics of $S$. nigra ssp. nigra cultivars in Europe, this study identified unique descriptors for juices from North American- 
grown cultivars not previously reported, including apple, beet, caramelized, fermented, processed, and pomegranate flavors, as well as astringent mouthfeel. In addition, elderberry juices produced in North America are most highly characterized by processed aroma and processed and elderberry flavors, but varied in nine sensory attributes, including fruity, floral, sweet aromatics, bitter, sour, and sweet flavors, bitter and sweet aftertastes, and astringent mouthfeel. Surprisingly, juice from 'Marge', which is a European elderberry, was indistinguishable from that of 'Bob Gordon' and 'Wyldewood' (American elderberries) for all sensory attributes except bitter flavor. Relative to other cultivars in this study, 'York' may be favored by juice processors due to its relatively low astringency and bitter aftertaste.

\section{Literature Cited}

Cavaliere, C., P. Rea, M.E. Lynch, and M. Blumenthal. 2010. Herbal supplement sales rise in all channels in 2009. HerbalGram 86:62-65.

Charlebois, D., P.L. Byers, C.E. Finn, and A.L. Thomas. 2010. Elderberry: Botany, horticulture, potential. Hort. Rev. 37:213-279.

Finn, C.E., A.L. Thomas, P.L. Byers, and S. Serçe. 2008. Evaluation of American (Sambucus canadensis) and European (S. nigra) elderberry genotypes grown in diverse environments and implications for cultivar development. HortScience 43:1385-1391.

Greene, D.W., R.A. Norton, C.R. Rom, R.L. Stebbins, and R. Way. 1997. The Brooks and Olmo register of fruit and nut varieties. 3rd ed. ASHS Press, Alexandria, VA.
Jensen, K., L.P. Christensen, M. Hansen, U. Jørgensen, and K. Kaack. 2001. Olfactory and quantitative analysis of volatiles in elderberry (Sambucus nigra L.) juice processed from seven cultivars. J. Sci. Food Agr. 81:237-244.

Kaack, K. 2008. Aroma composition and sensory quality of fruit juices processed from cultivars of elderberry (Sambucus nigra L.). Eur. Food Res. Technol. 227:45-56.

Kaack, K., L.P. Christensen, M. Hughes, and R. Eder. 2005. The relationship between sensory quality and volatile compounds in raw juice processed from elderberries (Sambucus nigra L.). Eur. Food Res. Technol. 221:244254.

Kaack, K., X.C. Fretté, L.P. Christensen, A.K. Landbo, and A. Meyer. 2008. Selection of elderberry (Sambucus nigra L.) genotypes best suited for the preparation of juice. Eur. Food Res. Technol. 226:843-855.

Kaplan, J., A. Matějíček, and J. Matějičková. 2015. Sensory evaluation of 17 elderberry cultivars grown in the Czech Republic. Acta Hort. 1061:215-218.

Konica Minolta. 2007. Precision color communication. Konica Minolta Sensing, Osaka, Japan. 27 Sept. 2016. <http://www.konicaminolta. com/instruments/knowledge/color/pdf/color_ communication.pdf>.

Lee, J. and C.E. Finn. 2007. Anthocyanins and other polyphenolics in American elderberry (Sambucus canadensis) and European elderberry (S. nigra) cultivars. J. Sci. Food Agr. 87:2665-2675.

McGuire, R.G. 1992. Reporting objective color measurements. HortScience 27:1254-1255.

Mohebalian, P., M.M. Cernusca, and F.X. Aguilar. 2012. Discovering niche markets for elderberry juice in the United States. HortTechnology 22:556-566.
Nakatani, N., H. Kikuzak, J. Hikida, M. Ohba, O. Inami, and I. Tamura. 1995. Acylated anthocyanins from fruits of Sambucus canadensis. Phytochemistry 3:755-757.

Özgen, M., J.C. Scheerens, R.N. Reese, and R.A. Miller. 2010. Total phenolics, anthocyanin contents and antioxidant capacity of selected elderberry (Sambucus canadensis L.) accessions. Pharmacogn. Mag. 6:198-203.

Perkins-Veazie, P., A.L. Thomas, P.L. Byers, and C. E. Finn. 2015. Fruit composition of elderberry (Sambucus spp.) genotypes grown in Oregon and Missouri, USA. Acta Hort. 1061:219-222.

Poll, L. and M.J. Lewis. 1986. Volatile components of elderberry juice. Lebensm. Wiss. Technol. 19:258-262.

Thomas, A.L., P.L. Byers, J.D. Avery, Jr., M. Kaps, and S. Gu. 2015a. Horticultural performance of eight American elderberry genotypes at three Missouri locations. Acta Hort. 1061:237-244.

Thomas, A.L., P.L. Byers, J.D. Avery, Jr., M. Kaps, S. Gu, H.Y. Johnson, and M. Millican. 2015b. 'Marge': A European elderberry for North American producers. Acta Hort. 1061:191199.

Thomas, A.L., P. Perkins-Veazie, P.L. Byers, C.E. Finn, and J. Lee. 2013. A comparison of fruit characteristics among diverse elderberry genotypes grown in Missouri and Oregon. J. Berry Res. 3:159-168.

Voss, D.H. 1992. Relating colorimeter measurement of plant color to the Royal Horticultural Society colour chart. HortScience 27:12561260.

Wu, H., M.C. Johnson, C.H. Lu, K.L. Fritsche, A.L. Thomas, Z. Cai, and C.M. Greenlief. 2015. Determination of anthocyanins and total polyphenols in a variety of elderberry juices by UPLC-MS/MS and other methods. Acta Hort. 1061:43-51. 